\title{
Brief report: Screening Prisoners for Intellectual Disabilities in Three English Prisons
}

Glynis H. Murphy+, Jeff Gardner*, \& Mark J. Freeman*

+Tizard Centre, University of Kent, Canterbury

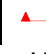

*Department of Health, Quarry House, Leeds

Formatted: English (U.K.)

Key words: Screening; CJS, prisons, offenders, ID 


\title{
Brief report: Screening Prisoners for Intellectual Disabilities in Three English Prisons
}

\author{
Abstract \\ Background Prisoners with intellectual disabilities are known to be disadvantaged in \\ prisons and to be more susceptible to bullying, segregation, depression and anxiety \\ than other prisoners. \\ Method In this study, nearly 3000 new prisoners entering 3 English prisons were \\ offered screening for intellectual disabilities, using the LDSQ. \\ Results On average $75 \%$ of all new prisoners entering prison were offered \\ screening, and only $14 \%$ refused screening. Overall just under $7 \%$ were screened \\ positive on the LDSQ and prisons made some reasonable adjustments as a result. \\ Conclusions It is argued that it is feasible to screen for intellectual disabilities in \\ prisons and, given the inequalities to which prisoners with intellectual disabilities are \\ subject in prison, it is time for such screening to be rolled out to all prisons.
}




\section{Introduction}

During the eugenics era, the stigmatisation of people with intellectual disabilities (ID) was probably even more common than it is now and, amongst the beliefs entertained, was the idea that people with ID were especially likely to break the law (eg. Goddard, 1912; Clarke, 1894, quoted in Brown and Courtless, 1971). Such concerns led to a large number of studies of the actual numbers of people with ID in the prison system (Woodward (1955), for example, quoted an analysis of over 300 such studies conducted between 1910 and 1928 in the USA).

Investigations into the prevalence of people with ID in the prison system have continued sporadically since then and they have led to divergent opinions. Figures from recent studies in a number of countries, summarised by Murphy \& Mason (2014, in their Table 1), showed that, generally, those where a full WAIS or other full $I Q$ test was used, resulted in lower prevalence figures, especially if adaptive behaviour measures were also completed (MacEachron, 1979; Murphy et al, 1995; Hayes et al, 2007; Herrington 2009; Holland and Persson, 2011), while studies using screening tests alone or measures short of the full gold-standard IQ test often produced higher prevalence figures (e.g. 10\% in USA, Brown \& Courtless, 1971; 7\% in Norway, Sondenaa et al, 2008; 29\% in Ireland according to Michael Murphy and colleagues, 2000; 19\% in Canada according to Crocker et al 2007).

It seems likely that prevalence rates for people with ID in prisons reported by the various studies will vary not just with the psychometric measures chosen, but also with the exact procedures employed in the studies (such as the degree of training for assessors and the times at which the tests are administered, eg. whether these are done at times when individuals may be highly stressed). It is also probable that the jurisdiction will influence prevalence rates (reflecting, for example, the possibilities of diversion from custody), and the types of CJS setting or prison in which the study takes place will also be an important variable (Noble and Conley, 1992; McBrien, 2003; Fazel et al, 2008; Uzieblo, Winter, Vanderfaeillie, Rossi \& Magez, 2012). Interestingly, at least until recently, despite the considerable research in this area, extremely few prisons or CJS settings seemed to use routine screening for ID within the UK (Talbot, 2008) or US (Scheyett, Vaughn, Taylor \& Parrish, 2009). 
Whatever the prevalence figures, people with intellectual disabilities are known to be very vulnerable in the Criminal Justice System. For example, they struggle to understand their rights in the police station (Clare \& Gudjonsson, 1991; Fulero and Everington, 1995; O'Connell et al, 2005) and often do not understand the Court process and legal language (Smith, 1993; Clare \& Gudjonsson, 1995; Kebbel et al, 2004; Talbot, 2008), so that they are liable to make false confessions (Gudjonsson, 1992; Leo \& Offshe, 1998; Drizin \& Leo, 2004; Perske, 2011; Kassin et al, 2010). Moreover, once they reach prison, people with ID are particularly disadvantaged by their difficulties in understanding written information (such as prison rules) and filling in forms (to order meals, book visitors or make doctor's appointments). They have been found to be more likely to be depressed, anxious and bullied than other prisoners, and are more frequently segregated (Talbot, 2008). Services that are designed to mitigate their disadvantages, such as the Appropriate Adult services in the police station, and work programmes or treatment programmes adapted to their needs in prison, are rarely offered (Bean and Nemitz, 1994; Medford et al, 2000; Talbot, 2008).

These difficulties for prisoners with intellectual disabilities, and the similar issues for people with mental health needs in prisons, recently led the UK government to commission a report on the matter. The resulting Bradley report (2009) made over 80 recommendations and one of these was that prisons should routinely screen for ID.

This project aimed to assess the feasibility and, to some extent, the utility of screening for ID, using a brief validated test that could be conducted by prison staff, following training. The aim was to screen every new prisoner in three large prisons, in order to discover the acceptability of the assessment to prison staff and prisoners, and to establish the number of prisoners identified as likely to have ID. It was anticipated that feasibility would be reflected in the percentage of all new prisoners offered screening, within 72 hours of admission to prison, and in the percentage of prisoners refusing screening. Utility was not formally measured but was reflected in the use that prisons made of the screening data. It should be noted that all three prisons completed this screening without extra resources, and it was prison staff who 
conducted the screening (unlike in all previous studies where researchers have been employed to conduct the screening).

\section{Method}

This study undertook screening for ID in three English (male) prisons. All three prisons were local category $B$ adult male prisons in city areas. Their capacities range from 1000-1500 prisoners approximately.

\section{Ethical approval}

The study was approved by the National Research Committee of the National Offender Management Service (NOMS) and by the Governor of each prison. Every prisoner gave informed consent, using an accessible information sheet and consent form, before being assessed, and it was made clear to prisoners that declining to take part in the research would not adversely affect their time in prison.

\section{Participants}

Three prisons took part in the project (prisons A, B, C). Each prison agreed to screen every new prisoner in a three-month period, provided they gave informed consent. Prisoners who were non-English speaking were excluded, in order to avoid possible over-identification (false positives) due to unfamiliarity with the English language, as well as possible under-identification (false negatives) due their likely lack of experience of community-based services (this issue is returned to later, in the Discussion section).

\section{Measure}

The screening tool used was the 'Learning Disability Screening Questionnaire' (LDSQ) ${ }^{1}$, which was originally developed to screen people for ID when they were referred to Community Learning Disability Teams (McKenzie \& Paxton, 2006a). This tool was chosen over other possible tools, such as the HASI (Hayes, 2002) and the LIPS (Mason \& Murphy, 2002) because it was validated (albeit in a relatively small

\footnotetext{
1 'Learning Disabilities' is the phrase used in the UK for intellectual disabilities (ID). The term used throughout this paper is intellectual disabilities, so as not to confuse international readers. 'Learning Disabilities' is only retained where necessary (in the names of community teams and in the name of the screening tool; it has the same meaning as ID).
} 
forensic sample of 94 individuals, see McKenzie et al, 2012), brief (7 items), required no special equipment and could be used by prison staff with minimal training (i.e. training of about 2 hours; it did not require the assessor to have particular qualifications, such as a psychology degree). In community services, the LDSQ had been shown to have a sensitivity of $91 \%$ and a specificity of $87 \%$ for detecting those with ID (McKenzie \& Paxton, 2006b), while in prisons and forensic in-patient units it was reported to have a sensitivity of $82 \%$ and specificity of $87.5 \%$ for detecting those with ID (McKenzie, Michie, Murray \& Hales, 2012). It was considered the best available validated screening tool suitable for use by prison staff.

\section{Procedure}

The staff responsible for assessing prisoners were trained in intellectual disability awareness and in how to administer the LDSQ questionnaire. Prison A chose to ask the Disability Liaison Officer to undertake the assessments; prison $B$ chose the Intellectual Disability nurse who worked in the prison; prison $\mathrm{C}$ chose prison staff in their education and skills department.

\section{Analysis and interpretation}

Data on prisoners were entered onto SPSS and analysed using simple descriptive and inferential statistics.

It is arguable that the most important statistics for interpreting screening tests are the positive predictive value (PPV) and the negative predictive value (NPV). The positive predictive value is the proportion of obtained positive results that are true positives; the negative predictive value is the proportion of obtained negative results that are true negatives. The PPV and NPV are not intrinsic to the test; they also depend on the prevalence of the characteristic being measured in the sample employed. Using the published true positives, false positive, true negatives and false negatives in McKenzie et al, 2012, then the PPV is $92.9 \%$ and the NPV is $74 \%$ for their sample. However, the McKenzie study took place in settings where ID was relatively common. In settings where it is less common the PPV can be expected to be lower and the NPV higher. For example, if the prevalence of ID in prisons were 1.5\% (Fazel et al, 2008), the PPV would be $9 \%$ and the NPV 93\%. The data obtained in this study were interpreted with these figures in mind. 


\section{Results}

Prisons were asked to screen the new prisoners in the first 72 hours if possible, but not all prisons managed this. Prison A screened on day 2 of induction, prison $B$ screened on days 3-5 of induction and prison $\mathrm{C}$ screened on day 7. In two prisons, one staff member was responsible for screening, which had the advantage of consistency but the disadvantage of gaps, if the person was away from the prison or otherwise engaged.

Table 1 shows the total numbers of new prisoners in the three-month trial period who entered the prisons (3778), together with the total number offered screening in each prison (2825). A small number refused to be screened (396), and some were not offered screening because the assessor was absent when they arrived or (more rarely) because they had serious mental health issues or lacked the capacity to consent. It should also be noted that 216 prisoners were not asked to complete the questionnaire because they were classified as "non-English" speaking. Of the total number of 2429 who were screened, 169 were identified as being more likely to have intellectual disabilities on the LDSQ (7\%) and the remainder were considered unlikely to have intellectual disabilities. The two prisons screening earlier (by day 5) offered screening to over $70 \%$ of new prisoners and had significantly lower refusal rates (below 15\%). The third prison, which screened prisoners later, offered screening to proportionately fewer prisoners (because of the 'churn', i.e. the rate at which prisoners were moved to other prisons) and had proportionately more refusals. The prisons differed significantly for proportions of prisoners offered screening (chi square $206.8, p<0.0001$ ) and proportions refusing screening once it was offered (chi square $264.8, p<0.0001)$.

\section{(Table 1 about here)}

The three prisons were not asked to do anything specific following screening, since the Ministry of Justice was not able to provide new resources for prisons.

Nevertheless, different prisons took different actions when someone was screened positive. In prison A, identified prisoners were referred, if they consented, to a third sector organisation that offered a variety of learning programmes in the prison and prepared prisoners for release into the community (signposting them onto 
appropriate community courses). In addition, again only with consent, all wing governors were advised about who had been identified. In prison B, prisoners identified were referred to the prison-based intellectual disabilities service, which had strong contacts with intellectual disabilities services outside the prison. Typically, in this prison, with consent, contact was made with the prisoner's local Community Learning Disability Team, who were invited into the prison to make contact with 'their' prisoner, allowing post-release planning. In prison C, those identified were referred to Education (in the prison) and reports were also sent to the prison Psychology Department for consideration for a more detailed assessment. Prison C said it was developing a care pathway for prisoners with ID whilst in prison, with healthcare input.

\section{Discussion}

Prisoners with ID are significantly disadvantaged in prisons in a variety of ways, and are more likely to be depressed and anxious, and less likely (for example) to see the doctor or have visitors, making their time in prison particularly difficult (Talbot, 2008).

In order to mitigate against the disadvantages that people with ID suffer in custody, prisons obviously need to identify which of their prisoners has ID. The gold standard assessment for determining ID entails a full assessment for both IQ and adaptive behaviour. Such IQ assessments are costly, can be very lengthy (over an hour per person) and have to be done by psychologists, who are in short supply in prisons. Moreover, assessments of adaptive behaviour are problematic in prisons, given that they normally rely on a third party report (i.e. someone who knows the prisoner well, and can describe his skills in a 'normal' environment). Given the numbers of new prisoners entering the three prisons in this study, such a gold standard assessment would not have been practicable. Nevertheless, it appeared that the LDSQ was a feasible substitute, requiring little training, no specialist professional qualifications, and taking little time (about 10 minutes). There was a cost to the LDSQ, though, as for many psychometric assessments, but it had the advantage of having been validated at least on a small sample (McKenzie et al, 2012), unlike many of the novel 'screening tests' being considered by NOMS. 
As regards feasibility, the relatively low refusal rates for screening, especially if screening was completed early (see Results and Table 1), indicated that the test was in the main acceptable to prisoners. The number of prisoners who were not offered screening, and the lengthy time before screening occurred in some prisons (see Results and Table 1), however, suggested that some prisons needed to commit more resources to the screening, as under-resourcing resulted in a chance of many men missing screening, due either to a staff member's absence, or a backlog in assessments and the 'churn' encountered when prisoners are moved out at short notice to another prison.

Of course, the LDSQ was only a screening tool. It was possible that the LDSQ, if anything, overestimated the number of prisoners with ID, since it did not measure as many cognitive skills as a full IQ test, and nor did it entail a detailed assessment of adaptive behaviour. Adaptive behaviour, though, is extremely hard to evaluate in prisons, as prisons are very restrictive environments that do not allow prisoners to engage in many of their adaptive behaviours. Moreover, the LDSQ validation data did take both IQ and adaptive behaviour into account, so that McKenzie et al (2012) would argue that the positive predictive value and negative predictive value they obtained do make it likely that those screened positive had intellectual disabilities. Nevertheless, it is recognised that PPV and NPV depend on the prevalence of the characteristic measured, and McKenzie et al's figures were obtained in forensic settings where intellectual disabilities were common (McKenzie et al, 2012), whereas the PPV and NPV are likely to be less favourable in settings like prisons if prevalence really is as low as $1.5 \%$ (Fazel et al, 2008). In any case, whatever screening test were used, good practice would dictate that anyone screened positive should have a further assessment to determine their support needs.

It seems that prisons adopted different strategies after screening a prisoner positive and all of the actions they took seemed appropriate, indicating some utility to the screening process. However, with more support and advice, it would be possible to extend the list of actions following a positive screen, to include, for example, 'easy read' versions of all relevant prison forms (including meal menus, visitor booking forms, doctor appointment forms), as well as adapted work programmes and treatment programmes to fit prisoners' needs. Some might argue that if the 
screening is over-inclusive, then not all of those identified may need extra support. Nevertheless, we would argue that such support will do no harm, even if a prisoner does not technically have an intellectual disability. Indeed it could be argued that these kinds of 'reasonable adjustments' may be suitable for many prisoners, given the high rates of specific learning disabilities, such as dyslexia (sometimes referred to as learning difficulties) in prisons (Dalteg \& Levander, 1998; Rasmussen et al, 2001).

This study had a number of shortcomings. The three prisons chosen were all local category $B$ prisons and they contained only about 4,000 prisoners out of the approximately 85,000 who were in custody at the time. Moreover, they were all adult male prisons so caution is necessary before any generalisation are made to other types of prisons. It was not possible, given the resources, to screen every single prisoner, so the results have also to be interpreted with this in mind. Moreover, it was a significant problem that the screening was not suitable for non-English speaking prisoners and this issue is important, given the numbers of people in prison without adequate English. Screening for non-English speaking prisoners needs research attention, but it will be a difficult issue, given that IQ tests are not culture-free. Finally, in an ideal world, it would have been preferable to have followed up prisoners screened positive on the LDSQ, with a full assessment on a gold-standard IQ test and adaptive behaviour measure, to check the extent that screening was accurately identifying people with intellectual disabilities. Unfortunately resources were not available for such a validation study. We relied instead on the published validation of the LDSQ (McKenzie et al, 2012) and we recognise that there is a need for a larger validation study for the LDSQ in forensic settings.

It is concluded that it was feasible to use the LDSQ in prisons, that few prisoners refused it and that the 3 prisons involved in the study had begun to try to implement improvements in their services for those screened positive. Given that screening for ID was recommended in the Bradley report (2009) and there is now a feasible method for screening prisoners, we would suggest that the National Offender Management Service (NOMS) needs to roll out ID screening to all prisons, as a first step to ensuring that people with ID are not disadvantaged during their time in prison. We would argue that the LDSQ is a suitable instrument for this although, as 
with many assessments, there is an associated cost. Currently NOMS is in breach of the Equality Act 2000 in not making reasonable adjustments for people with ID (and, for example, in not having a complete set of offender behaviour programmes that they can access in prison). Moreover, in the longer term, given that it has been wellestablished for years that people with ID are disadvantaged in the police station (Clare \& Gudjonsson, 1995; Medford et al, 2000; Kassin et al, 2010) and in courts (Kebbel et al, 2004; Talbot, 2008), as well as in prisons, both in this country and elsewhere (Murphy \& Clare, 2009; Perske, 2011; Murphy \& Mason 2014), it would seem sensible to screen people at an earlier stage, such as on arrest at the police station (Young, Goodwin, Sedgwick \& Gudjonsson, 2013), so that the difficulties that the person has could be taken into account throughout his/her journey through the CJS.

\section{Acknowledgements}

The authors are grateful for the help of the very committed staff in all three prisons and for all prisoners who volunteered, without whom this study could not have been completed. This study was funded by the Department of Health.

\section{Conflicts of interest}

None. 


\section{References}

Bradley K. (2009). Lord Bradley's review of people with mental health problems or learning disabilities in the criminal justice system.

www.dh.gov.uk/en/Publicationsandstatistics/Publications/PublicationsPolicyAn dGuidance/DH 098694

Bean, P. \& Nemitz, T. (1994) Out of Depth and Out of Sight. London: Mencap.

Brown, B.S. \& Courtless, T.F. (1971) The Mentally Retarded Offender.

Washington DC: U.S. Government Printing Office, Dept of Health Education and Welfare Publication No. 72-90-39.

Clare, I.C.H. \& Gudjonsson, G.H. (1991) Recall and understanding of the caution and rights in police detention among persons of average intellectual ability and persons with a mental handicap. Proceedings of the First DCLP Annual Conference, 1, 34-42. Leicester: British Psychological Society (Issues in Criminological and Legal Psychology Series, No. 17).

Clare, I.C.H. \& Gudjonsson, G.H. (1995) The vulnerability of suspects with intellectual disabilities during police interviews: a review and experimental study of decision-making. Mental Handicap Research, 8, 110-128.

Crocker, A.G., Cote, G., Toupin, J. St-Onge, B. (2007). Rate and characteristics of men with an intellectual disability in pre-trial detention. Journal of Intellectual \& Developmental Disability, 32, 143-152.

Dalteg, A. \& Levander, S. (1998) twelve thousand crimes by 75 boys: a 20 year follow-up study of childhood activity. Journal of Forensic Psychiatry, 9, 39-57.

Drizin, S.A. \& Leo, R.A. (2004). The problem of false confessions in the postDNA world. North Carolina Law Review, 82, 891-1007. 
Fazel, S., Xenitidis, K \& Powell, J. (2008). The prevalence of intellectual disabilities among 12000 prisoners: a systematic review. International Journal of Law \& Psychiatry, 31, 369-373.

Fulero, S.M. \& Everington, C. (1995) Assessing competence to waive Miranda rights in defendants with mental retardation. Law and Human Behaviour, 19, 533-543.

Goddard, H.H. (1912) How shall we educate mental defectives? The Training School Bulletin, 9, 43.

Gudjonsson, G.H. (1992) The Psychology of Interrogations, Confessions and Testimony. Chichester: John Wiley and Sons.

Hayes, S. C. (2002). Early intervention or early incarceration? Using a screening test for intellectual disability in the Criminal Justice System. Journal of Applied Research in Intellectual Disabilities, 15: 120-128.

Hayes, S., Shackell, P., Mottram, P. \& Lancaster, R. (2007). The prevalence Formatted: English (U.K.) of intellectual disability in a major UK prison. British Journal of Learning Disability, 35, 162-167.

Herrington, V. (2009). Assessing the prevalence of intellectual disability among young male prisoners. Journal of Intellectual Disability Research, 53, 397-410.

Holland, S. \& Persson, P. (2011). Intellectual disability in the Victorian prison system: characteristics of prisoners with an intellectual disability released from prison in 2003-2006. Psychology, Crime \& Law, 17, 25-41.

Kassin, S.M., Drizin, S.A., Grisso, T., Gudjonsson, G.H., Leo, R.A. \& Redlich, A.D. (2010). Police-induced confessions: Risk factors and recommendations. Law \& Human Behavior, 34, 3-38.

Kebbel, M., Hatton, C. \& Johnson, S. (2004) Witnesses with intellectual disabilities in court: What questions are asked and what influence do they have? Legal and Criminological Psychology, 9, 23-35. 
Leo, R.A. \& Offshe, R.J. (1998). The consequences of false confessions: Deprivations of liberty and miscarriages of justice in the age of psychological interrogation. Journal of Criminal Law and Criminology, 88, 429-496.

MacEachron, A. E. (1979). Mentally retarded offenders: prevalence and characteristics. American Journal of Mental Deficiency, 84, 165-76.

Mason, J. \& Murphy, G.H. (2002). People with an intellectual disability in the criminal justice system: developing an assessment tool for measuring prevalence. British Journal of Clinical Psychology, 41: 315-320

McBrien, J. (2003). The intellectually disabled offender: methodological problems in identification. Journal of Applied Research in Intellectual Disabilities, 16, 95-105.

McKenzie, K., Michie, A., Murray, A. \& Hales C. (2012). Screening for offenders with an intellectual disability: the validity of the Learning Disability Screening Questionnaire. Research in Developmental Disabilities, 33: 791 795.

McKenzie, K. \& Paxton, D. (2006a) Learning Disability Screening Questionnaire. Edinburgh: GCM Records.

McKenzie, K. \& Paxton, D. (2006b) Promoting access to services: the development of a new screening tool. Learning Disability Practice, 9: 17-21.

Medford, S., Gudjonsson, G. \& Pearse, J. (2000) The Identification of Persons at Risk in Police Custody: The Use of Appropriate Adults by the Metropolitan Police. Published by the Metropolitan Police.

Murphy, G. \& Clare, I.C.H. (2009). Intellectual disabilities. In S. Young, M. Kopelman, \& G.H. Gudjonsson (Eds) Forensic Neuropsychology in Practice. Oxford University Press. Pp 53- 79. 
Murphy, G.H., Harnett, H., Holland A.J. (1995) A survey of intellectual disabilities amongst men on remand in prison. Mental Handicap Research 1995; 8: 81-98

Murphy, G.H. \& Mason, J. (2014) Forensic and offending behaviours. In Handbook of Psychopathology in Intellectual Disability (Eds E. Tsakanikos and J. McCarthy). New York: Springer Science.

Noble, J.H. \& Conley, R.W. (1992) Toward an epidemiology of relevant attributes. In R.W. Conley, Luckasson, R. \& G.N. Bouthilet (Eds.) The Criminal Justice System and Mental Retardation. Baltimore, Maryland: Paul H. Brookes. pp. 17-53.

O'Connell, M.J., Garmoe, W. \& Goldstein, N.E. (2005). Miranda comprehension in adults with mental retardation and the effects of feedback style on suggestibility. Law and Human Behavior, 29, 359-369.

Perske, R. (2011). Perske's list: False confessions from 75 persons with intellectual disability. Intellectual and Developmental Disabilities, 49, 365-373.

Rasmussen, K, Almvik, R. \& Levander, S. (2001) AD/HD, reading disability and personality disorders in a prison population. Journal of the American Academy of Psychiatry \& Law, 29, 186-193.

Scheyett, A., Vaughn, J., Taloy, M. \& Parish, S. (2009). Are we there yet? Screening processes for intellectual and developmental disabilities in jail settings. Intellectual and Developmental Disabilities, 47, 13-23.

Smith, S.A. (1993) Confusing the terms "guilty" and "not guilty": Implications for alleged offenders with mental retardation. Psychological Reports, 73, 675678.

Sondenaa, E., Rasmussent, K., Palmstierna, T. \& Nottesstad, J. (2008). The prevalence and nature of intellectual disability in Norwegian prisons. Journal of Intellectual Disability Research, 52, 1129-1137. 
Talbot J. (2008) Prisoners' Voices: Experiences of the Criminal Justice System by Prisoners with Learning Disabilities and Difficulties. London: Prison Reform Trust.

Uzieblo, K., Winter, J., Vanderfaeillie, J., Rossi, G. \& Magez, W. (2012). Intelligent diagnosing of intellectual disabilities in offenders: Food for thought. Behavioral Sciences \& the Law, 30, 28-48.

Young, S., Goodwin, E., Sedgwick, O., Gudjonsson, G.H. (2013) The effectiveness of police custody assessment in identifying suspects with intellectual disabilities and attention deficit hyperactivity disorder. BMC Medicine, 11, 248. 
Table 1. Numbers of prisoners offered screening, numbers screened, numbers refused and numbers identified as having ID in the three prisons

\begin{tabular}{|l|l|l|l|l|}
\hline & $\begin{array}{l}\text { Total number } \\
\text { of new } \\
\text { prisoners }\end{array}$ & $\begin{array}{l}\text { Total number } \\
\text { offered } \\
\text { screening }(\% \\
\text { of all new } \\
\text { prisoners) }\end{array}$ & $\begin{array}{l}\text { Total number } \\
\text { refused to be } \\
\text { screened } \\
\text { of those } \\
\text { offered } \\
\text { screening) }\end{array}$ & $\begin{array}{l}\text { Number } \\
\text { identified with } \\
\text { intellectual } \\
\text { disabilities (\% } \\
\text { of those } \\
\text { screened) }\end{array}$ \\
\hline Prison A & 1600 & $1364(85.3 \%)$ & $195(14.3 \%)$ & $59(5.0 \%)$ \\
\hline Prison B & 1546 & $1099(71.1 \%)$ & $58(5.3 \%)$ & $89(8.5 \%)$ \\
\hline Prison C & 632 & $362(57.3 \%)$ & $143(39.5 \%)$ & $21(9.6 \%)$ \\
\hline Overall & 3778 & $2825(74.8 \%)$ & $396(14.0 \%)$ & $169(6.9 \%)$ \\
\hline
\end{tabular}

